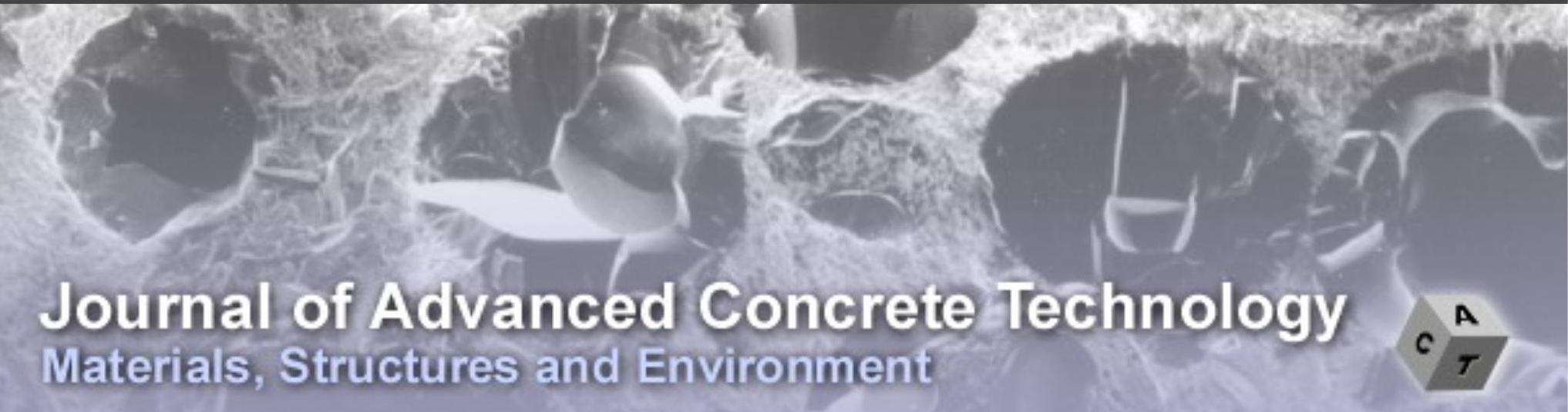

\title{
Fire Resistance of Reinforced Concrete Frames Subjected to Service Load: Part 1. Experimental Study
}

Mohammad Mahdi Raouffard, Minehiro Nishiyama

Journal of Advanced Concrete Technology, volume 13 (2015), pp. 554-563

\section{Related Papers Click to Download full PDF!}

\section{Transport Properties of Fire-Exposed Concrete}

Wilasa Vichit-Vadakan, Elizabeth A.Kerr

Journal of Advanced Concrete Technology, volume 7 (2009), pp. 393-401

An advanced transient concrete model for the determination of restraint in concrete structures subjecte to fire

Martin Schneider, Ulrich Schneider

Journal of Advanced Concrete Technology, volume 7 (2009), pp. 403-413

Fire Behaviour of Circular Concrete Columns with Restrained Thermal Elongation

Joao Paulo C. Rodrigues, Luis Laim, Manfred Korzen

Journal of Advanced Concrete Technology, volume 12 (2014), pp. 289-298

Flexural behavior of fire-damaged reinforced concrete slabs repaired with near-surfaced mounted (NSM carbon fiber reinforced polymer (CFRP) rods

Cao Nguyen Thi, Withit Pansuk, Lluis Torres

Journal of Advanced Concrete Technology, volume 13 (2015), pp. 15-29

\section{Click to Submit your Papers}




\title{
Scientific paper
}

\section{Fire Resistance of Reinforced Concrete Frames Subjected to Service Load: Part 1. Experimental Study}

\author{
Mohammad Mahdi Raouffard $^{1^{*}}$ and Minehiro Nishiyama ${ }^{2}$
}

\begin{abstract}
This paper describes the results of fire tests, which were carried out to study the behavior of moment-resisting reinforced concrete frame at elevated temperatures. The continuity of the beams with the columns generates considerable internal forces and rotation demands, which in turn could have detrimental (geometrical second order effect) and/or beneficial (increasing load bearing capacity) influences on the fire resistance of the global structure. In this paper, two $1 / 3$ scale statically indeterminate RC frames, RCF1 and RCF2, under service loads were exposed to the ISO-834 fire. The target frame was a two-storey frame, in which the lower columns and middle beam were under fire attack. RCF1 was heated for 175 minutes until eventually its concrete beam failed from the excessive flexural cracks and deformations, whereas RCF2 was heated for 60 minutes until the temperature of the tensile reinforcements of its beam reached $550^{\circ} \mathrm{C}$. The beam ends and the joints relatively attained lower internal temperatures owing to the unheated upper columns. The axial and moment restraints significantly increased the load bearing capacity of the fire-attacked beams without occurrence of any failure at the side columns and joints.
\end{abstract}

\section{Introduction}

\subsection{Fire-safety design approach for RC frame}

Moment-resisting reinforced concrete $(\mathrm{RC})$ frame is a very common load bearing structure, especially for buildings with high risk of occurrence of extreme lateral disturbance such as earthquake or strong winds. Fire endurance of such structures is mainly dependent upon the fire resistance of the constituent elements, i.e., beams, columns, joints, and the interaction between them. During the past couple of decades many fire tests on individual RC beams and columns with different constraint conditions have been carried out and the results have been well documented and codified into a series of tabulated fire safety design guidelines, known as prescriptive design code. The prescriptive design approach determines minimum concrete cover for the reinforcements and/or section dimensions for an individual member for a required fire resistance rating. The term fire resistance rating in the codes is generally a measure of the ability of the structure to resist collapse, fire spread, or other failure during exposure to a fire with specific destructive impact to a fire of specified severity, and fire severity is a measure of a destructive impact of a fire which could cause collapse or other

${ }^{1} \mathrm{PhD}$ Candidate, Department of Architecture and Architectural Engineering, Kyoto University, Kyoto, Japan.

*Corresponding author,

E-mail:m.m.raouffard@gmail.com

${ }^{1}$ Professor, Department of Architecture and Architectural Engineering, Kyoto University, Kyoto, Japan. failure as a result of the fire (Buchannan 2001). Thus, the fire resistance of an element should be greater than the severity of fire to which the member is exposed. This verification is usually time domain, through which the time to failure under standard fire conditions is checked. Fig. 1 shows the fire ratings required by the Article 107 of Japanese building standard law (AIJ 1998). In this figure, the very first floors of a 17-stoery building, for instance, should prevent any collapse within at least three hours under the standard fires designated in the code.

Structural designers with little knowledge about fire safety engineering would rather adopt the abovemen-

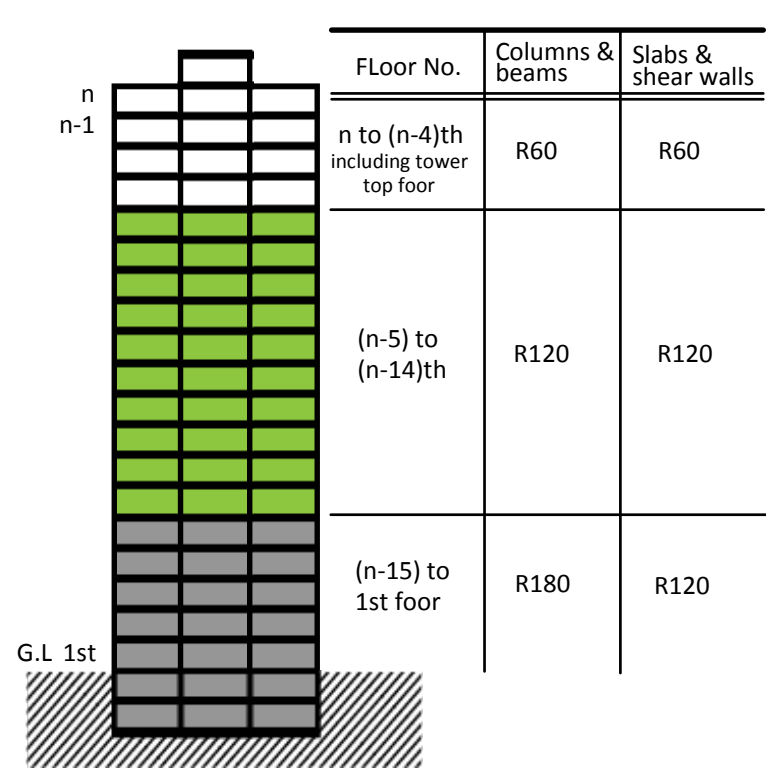

Fig. 1 Required fire resistance ratings for building structures in Japan. 
tioned tabulated design approach as it is simple and fast. However, in some cases fulfilling these codes could be restrictive, uneconomical, and even unsafe design (Wang et al. 2012). Assume a building fire breaks out in a multi-storey and multi-span RC frame as is schematically illustrated in Fig. 2. In such a redundant complex structure, the interaction between the heated members and the restraint by the surrounding unheated frames can have both beneficial and detrimental effects to the global structure. While the load bearing capacity of the heated beam can take advantage of its restrained thermal expansions (Saito 1968), the occurrence of excessive drifts in the exterior columns in Fig. 2(a) increases the vulnerability to second order effects, such as shear failure or column buckling (Fletcher et al. 2006; Chana and Price 2003). The shortcoming of the prescriptive design approach in considering the interaction of individual members in a complex structure, can be largely compensated by practicing of advanced fire resistance calculation methods, known as performance based design (PBD). PBD has greatly advanced in the past 20 years by improvement of material constitutive models at elevated temperatures and has already been adopted in many recent major projects (Luo et al. 2005; Takeichi and Minegishi 2015). Bisby et al. (2014) identified a number of research priorities needed to be fulfilled to achieve inclusive PBD. One of these priorities is of interest to the topic of this study: providing experimental results on structural continuity to be used for verifying numerical models.

\subsection{Previous fire tests on RC frames}

Bailey (2002) and Chana and Price (2003) reported the results of a natural fire test on a full-scale, seven-storey cast in-place concrete building in the BRE Cardington test site. The test had several objectives, two of which were to investigate how the whole structure accommodated large thermal expansions from heated members, and to identify both beneficial and detrimental modes of whole building that cannot be observed in standard fire tests on individual structural elements. It was found that the detrimental effect of thermal expansion caused significant lateral movements of the external columns, resulting in additional stresses in the column due to the P$\Delta$ effect. Xiao Jian et al. (2008) carried out fire tests on three single-span and single-storey frames cast with high performance concrete (HPC) of blast furnace slag to investigate fire response and post-fire seismic performance of the frames. Some cracks at the joints occurred as a result of moment redistribution, which in turn weakened the post-fire seismic resistance of the frames. Fang et al. (2012) carried out two full-scale fire tests on external beam-column subassemblages (three hours heating) to investigate the fire resistance and residual performance of part of a seven-story residential building designed for seismic conditions. The frames were cast with self-consolidating concrete and HPC. The researchers concluded that even though during

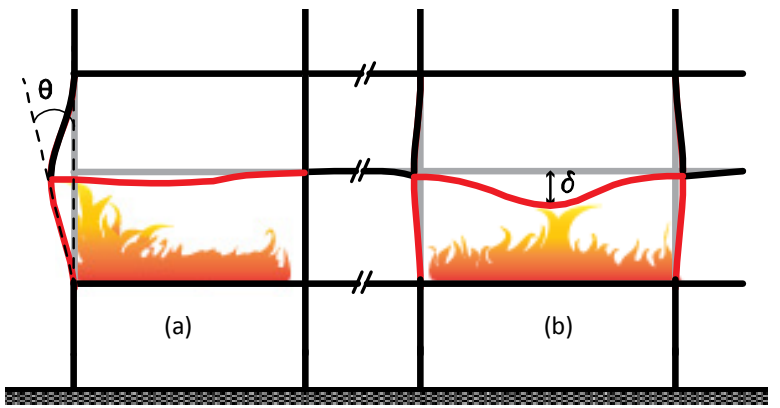

Fig.2 RC frame in fire: (a) extrenal beam-column subassamblage, (b) internal frame (deflections and deformations are exaggerated).

early stages of heating severe explosive spalling of concrete occurred, the beam-column sub-assemblages could resist the service loads much better than any prescriptive design could predict.

\subsection{Research objectives}

In this paper, in an attempt to study the fire resistance of concrete frame designed in accordance with seismic building code of Japan, the authors carried out the ISO 834-1 standard fire test on two identical statically indeterminate concrete frames, RCF1 and RCF2. The frames were subjected to constant service loads during heating. Fig. 2(b) is the target frame for this study, which is a lower storey of a two-storey sub-frame of a typical multi-storey residential RC building. The fire was assumed to breakout at the lower storey so that the lower columns and the middle beam were directly under fire attack. The test specimen RCF1 was heated to collapse and the test specimen RCF2 was heated for one hour to investigate its residual load bearing capacity in post fire conditions. The experimental works aimed to:

- propose a simple fire test method for momentresisting $\mathrm{RC}$ frame structures;

- trace the internal temperature distributions within the test specimens;

- observe the fire damage during and after the fire tests;

- measure the structural responses of the frame test specimens;

- investigate the fire response of the joints with headed (mechanical) and 90-degree hook anchorages;

- trace collapse mechanism of RCF1;

- measure post-fire residual load bearing capacity of RCF2; and

- provide experimental results for development, assessment, and validation of future numerical studies.

The post-fire residual load bearing capacity of test specimen RCF2 is beyond the scope of this paper. Hence, the results will be published elsewhere.

\section{Experimental work}

\subsection{Test specimen design and construction}

For the purpose of this experimental work two 1/3 scaled test specimens were designed and constructed. 
Table 1 Concrete mix and mechanical properties.

\begin{tabular}{c|c|c|c|c|c}
\hline Cement type & Slump $(\mathrm{cm})$ & W/C $(\%)$ & Moisture content $(\%)$ & Compressive strength $\left(\mathrm{N} / \mathrm{mm}^{2}\right)$ & Young's modulus $\left(\mathrm{kN} / \mathrm{mm}^{2}\right)$ \\
\hline Normal Portland & 15 & 63 & 5.9 & 31.3 & 25.7 \\
\hline
\end{tabular}

Table 2 Reinforcement mechanical properties.

\begin{tabular}{c|c|c|c|c}
\hline Type & Location & Area $\left(\mathrm{mm}^{2}\right)$ & Yielding strength $\left(\mathrm{N} / \mathrm{mm}^{2}\right)$ & Young's modulus $\left(\mathrm{kN} / \mathrm{mm}^{2}\right)$ \\
\hline D19 SD345 & Beam long. reinforcement & 286.5 & 408 & 188 \\
\hline D16 SD295 & Column long. reinforcement & 198.6 & 351 & 191 \\
\hline D10 SD295 & Lateral reinforcement & 71.3 & 377 & 200 \\
\hline
\end{tabular}

Fig. 3(a) shows the details of the test frames. The test specimens consisted of an H-shape RC structure and two upper and lower steel beams. The steel beams were fixed to the concrete structure via prestressing steel rods. The dimensions of the cross-sections of the RC columns and beams were $250 \times 250$ and $200 \times 250 \mathrm{~mm}$, respectively. According to AIJ standard for structural calculation of RC structures (AIJ RC Code), $40 \mathrm{~mm}$ to the centre of the longitudinal reinforcements concrete cover thickness was considered to meet 60-minute fire rating. Steel bars type D19 and D16 were used in design as the main reinforcements for the beam and column sections, respectively. Normal concrete with $30 \mathrm{MPa}$ nominal compressive strength was cast. The cast concrete mixture and its mechanical properties are summarized in Table 1. The mechanical properties of the steel bars are shown in Table 2, as well. Two $30.9 \mathrm{kN}$ service loads were calculated based on the allowable stress design method of Japan (AIJ RC Code). This design method considers one-third of concrete compressive strength (in this study $10 \mathrm{MPa}$ ) and $215 \mathrm{MPa}$ allowable stress value for reinforcing steels. The loads were symmetrically applied to $400 \mathrm{~mm}$ from the mid-span of the beam. D10 transverse reinforcements with 80 and $70 \mathrm{~mm}$ spacing were calculated for the beam and columns, respectively. The bending moment diagram of the test specimen is shown in Fig. 3(b). The design details of the anchorages are shown in Fig. 3(c). As can be seen in the figure, the left and the right beam ends anchored to their side columns with 90-degree hook and headed (mechanical) anchorages, respectively. Moreover, the ends of the longitudinal reinforcements of columns were welded to 20 mm-thick cap steel plates.

The yielding moment capacities of the beam and columns were 43.3 and $52.0 \mathrm{kN} . \mathrm{m}$, respectively (Eq. 1). The shear capacities of the beam and columns were 81.70 and $96.93 \mathrm{kN}$, respectively, as well. The ultimate shear capacity of the joints was $272.5 \mathrm{kN}$ (Eq. 2). The two top and bottom steel beams were H-shape SS400 type beams $(250 \times 250 \times 9 \times 14)$ with $157 \mathrm{MPa}$ allowable compressive-flexural stress limit. Each steel beam was attached to the side concrete columns via four $26 \mathrm{~mm}$

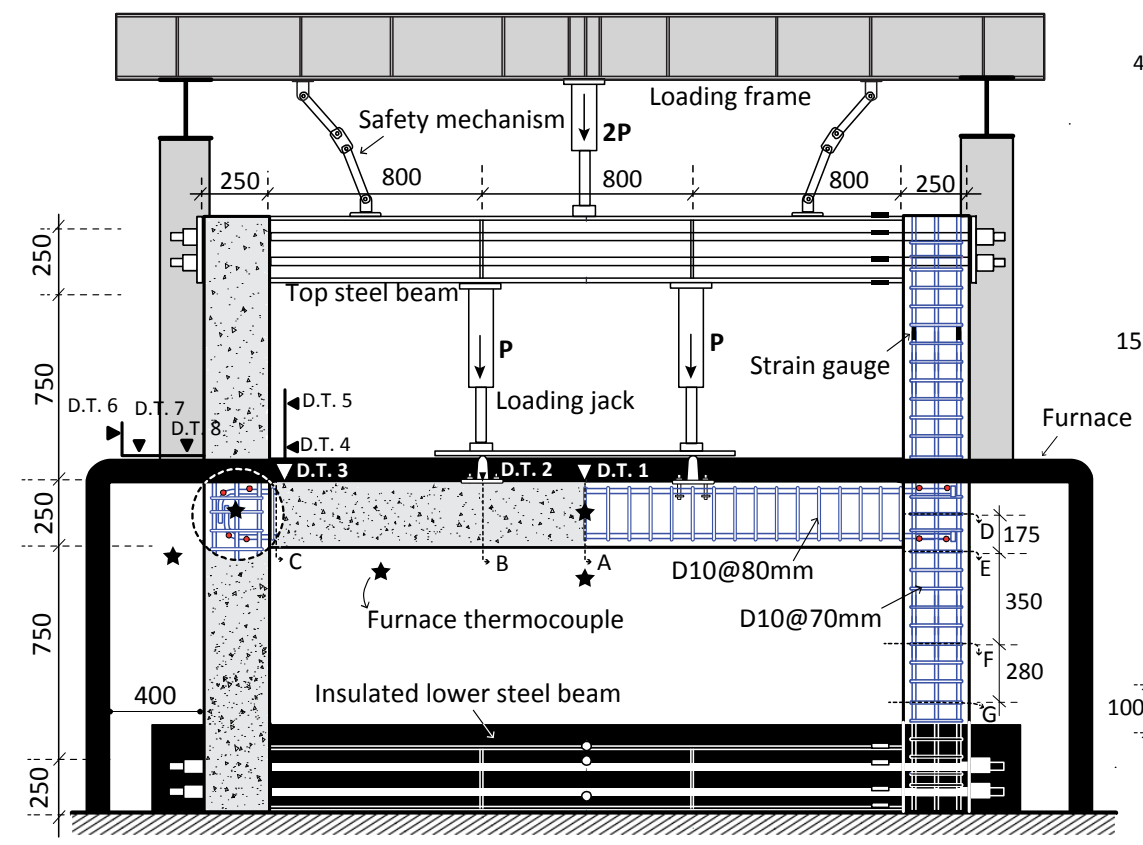

(a) Test specimen geometry (unit: $\mathrm{mm}$ )

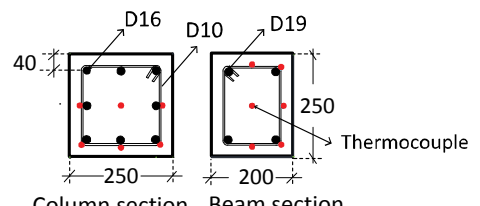

Column section Beam section

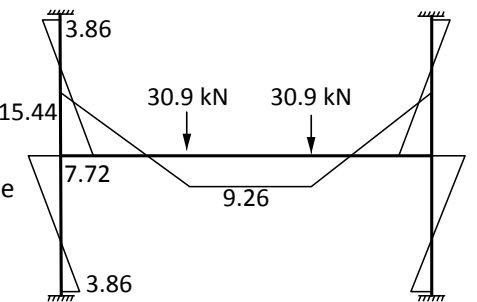

(b) Bending moment diagram

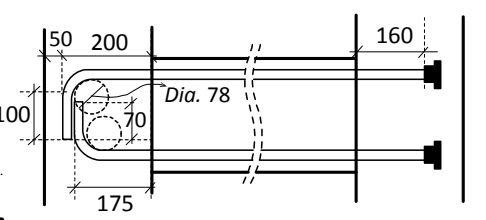

(c) Anchorage details

Fig. 3 Test specimen details. 
diameter steel rods (type SBPR 1080/1230) subjected to $141 \mathrm{kN}$ post-tensioned load each. The post-tensioning load was calculated so as to construct sound integrity at the top and bottom L-shape joints. The steel-tensioning work was carried out 90 days after concrete casting, one day before the fire tests. The steel beams and rods were reusable after completion of the fire tests.

\subsection{Test setup}

\subsubsection{Furnace and test specimen placement}

The first storey of the test specimens were installed in a full-scale gas furnace located at the General Building Research Corporation or GBRC in Osaka. The furnace is capable of conducting fire test in accordance with the ISO 834-1 (1999) fire resistance tests. The details of the furnace are shown in Fig. 3(a) and Fig. 4. The side walls of the furnace were equipped with Eight $100 \times 100$ $\mathrm{mm}$ windows, through which the general condition of the test specimens during heating was observable. The thermal boundaries were the lower columns, the middle beam (except top face), and the beam-column connections. $100 \mathrm{~mm}$ thick anti-fire ALC panels were bolted to the top face of the $\mathrm{RC}$ beam to insulate its top face and also provide stiff supports for the top doors of the furnace. The bottom steel beam, which was inevitably inside the furnace, was shielded with several ceramic sheets and gypsum paste.

\subsubsection{Loading setup}

A steel scaffolding was installed outside the furnace to support the hydraulic jacks and displacement transducers. Two hydraulic jacks, which were supported to the lower flanges of the top beams, applied the vertical loads to the RC beam. The tensile forces in the upper columns due to this loading setup were cancelled by another hydraulic jack which was installed on the top flange of the upper steel beam. The top steel beam was strengthened by some stiffeners to increase its flexural stiffness.

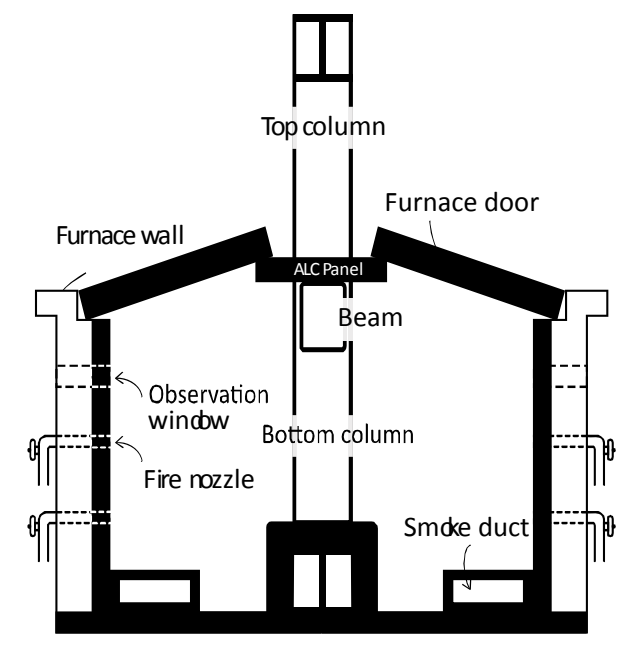

Fig. 4 Placement of test specimen and furnace details.

\subsubsection{Measuring instruments}

The applied loads were measured by the load cells placed at the loading points. Several displacement transducers (DT) measured the structural responses of the test specimens such as vertical deflections, rotations, and deflections. The steel beams and the main reinforcements of the upper columns were equipped with strain gauge to calculate the changes in the bending moment diagram during the fire tests. Five crosssections of the RC beam (the beam ends, the loading points and the mid-span cross-sections) and three crosssections of each lower columns (the top, the middle, and the bottom cross-sections) were equipped with six $\varphi 0.65$ JIS Class II thermocouples by which the temperatures of the core concrete, stirrups, and reinforcing bars of the cross-sections were captured. The internal temperature of the furnace was measured by eleven beam type thermocouples marked in Fig. 3(a).

\subsection{Test procedure}

One hour before the commencement of fire, the loads were gradually applied to prevent any dynamic effects. The initial cracks were marked on the worksheets. Next, the top doors of the furnace were closed and the gaps were filled with gypsum paste. Afterwards, the fire started. The furnace's temperature and pressure were constantly measured and controlled. The general behavior of the test specimens during heating process was observed through the embedded windows on the furnace walls. The fire for RCF1 terminated 174.5 minutes from the start of heating when the loaded beam could no longer sustain constant loading. On the other hand, RCF2 was heated roughly 60 minutes until the temperature of the tensile reinforcements of its $\mathrm{RC}$ beam reached $550 \mathrm{oC}$ at which the residual yield stress of the steel reinforcing $f_{v, 550^{\circ} \mathrm{C}}$, was expected to roughly reduce to $0.5 f_{y, 20^{\circ} \mathrm{C}}$ (AIJ 2009). After fire termination, the test specimens were unloaded but kept in the furnace for an extra one hour to cool down. Finally after removing the furnace top doors, the frames were lifted out for damage inspection.

\section{Test results}

\subsection{Damage pattern \\ 3.1.1 RC beam}

Figure 5 shows the extent of damage to the beam of RCF1 after fire. The beam exhibited remarkable residual deflections at its mid-sections and rotations at its restrained ends. No spalling of concrete was detected. Severe flexural cracks as wide as $10 \mathrm{~mm}$ at the mid sections occurred. Flexural shear and shear cracks were the major damages between the loading points and the beam ends. In Fig. 5(b) and 5(c) the damage to the beam ends are shown. The flexural cracks at the beam end crosssections diagonally extended to the joints forming some shear cracks. In contrast, minor damage was observed in test specimen RCF2. It should be noted that the forma- 


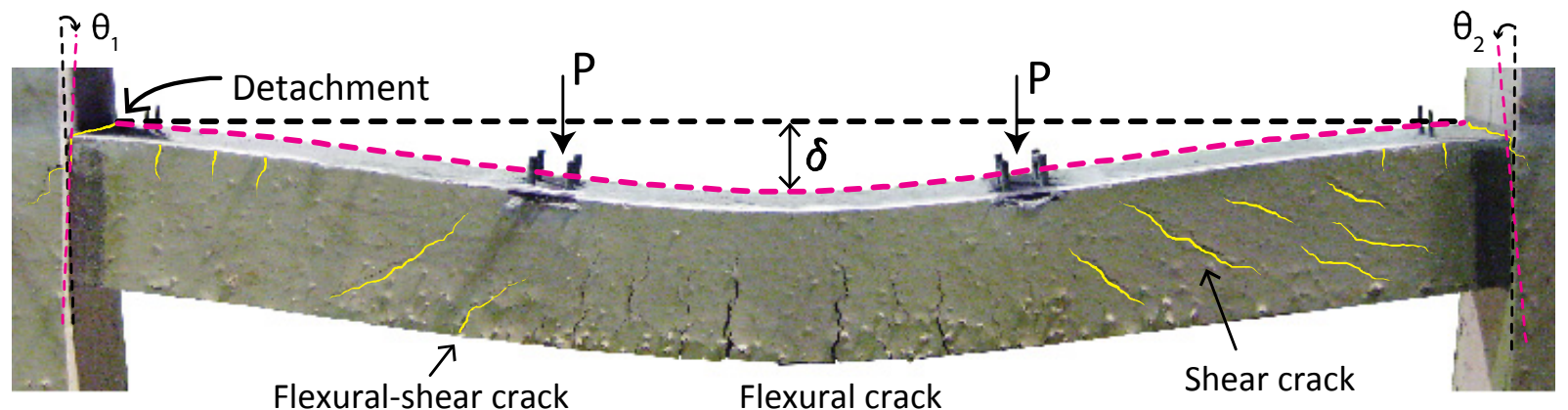

(a) major crack pattern

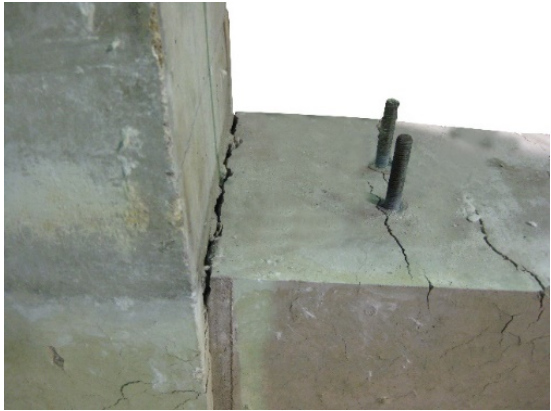

(b) 8-mm wide crack at left beam end

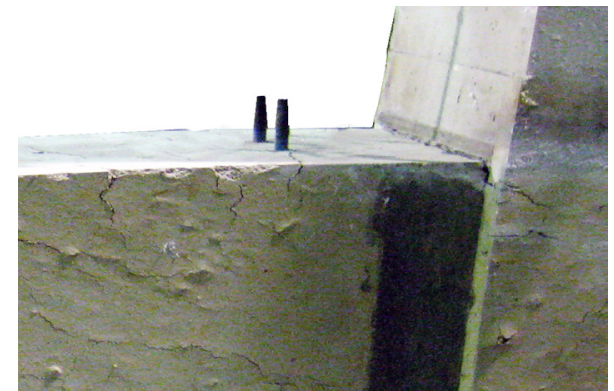

(c) Damage of right beam end

Fig. 5 Global aspect of RCF1 beam after fire.

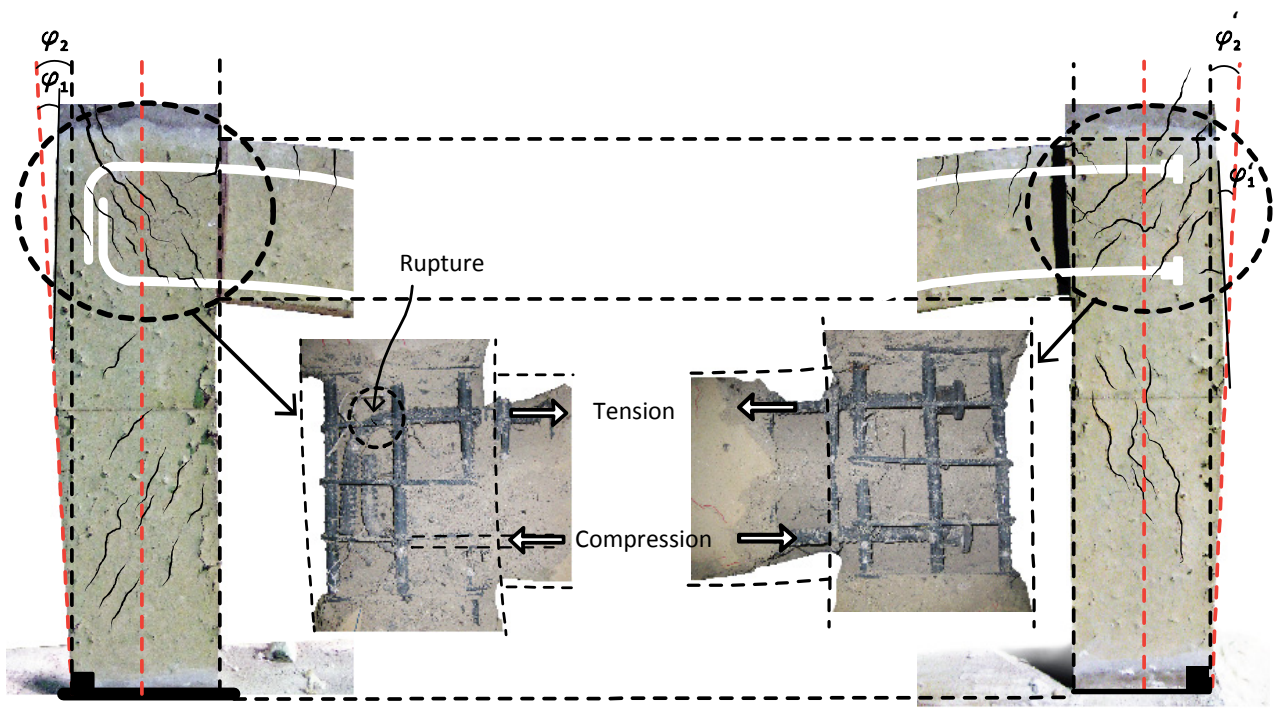

(a) Left lower column \& joint (hook anchorage)

(a) left column and joint (hook anchorage) (b) Right lower column \& joint (headed anchorage)

(b) Right column and joint (headed anchorage)

Fig. 6 Post-fire global aspect of RCF1 columns and joints.

tion and/or widening of some of the detected cracks could occur during cooling phase. Tracking the propagation of cracks through the small size observation windows on the walls of furnace with the naked eyes was very difficult.

\subsubsection{Joints and columns}

The damage to the lower columns and the joints of RCF1 are shown in Fig. 6. As it is marked on the photographs of the deformed members, the dominant damage is shear crack. The shear cracks of the lower columns reveal the effect of thermal expansion of the beam in deforming the fire-attacked columns. Similarly, the joints accommodated several shear cracks, some of which extended to the unheated upper columns. The core concrete of the joints were partially removed to observe the conditions of the anchorages. The transverse reinforcements apparently maintained the integrity of the joints. However, the bent bars of the hook anchorage were slightly dislocated and a rupture was detected on 
the upper bent bar. No damage occurred in the headed anchorage.

\subsection{Internal temperature distributions \\ 3.2.1 RC beam}

Figure 7 shows the recorded temperatures of the furnace together with the ISO-834 standard fire curve as a function of time. The initial temperature fluctuations of the furnace decreased as the heating continued. Figure 8 shows the recorded internal temperature distributions within the left half of the beam of RCF1. The thermal cross-sections of the other half were roughly similar to those of the left side and thus, are not presented here.

As can be seen in the figures, there is a similar temperature rise pattern in the core concrete (thermocouple No. 1) and beneath the ALC panels (thermocouple No.2). The concrete in these locations, especially the core concrete, exhibited a lengthy plateau in the temperature curves (temperature stagnation) roughly at $100^{\circ} \mathrm{C}$ for approximately one hour. This behavior is attributed to the evaporation of free water contents of the outer layers, which increased the pore pressure of the heated layers. The accumulated pore pressure partly released as water vapor into the furnace and the remainder were damped and condensed in the inner cooler concrete layers.

The beam ends apparently attained lower temperatures at locations close to the heated faces (thermocouples 4,5 , and 6). This thermal gradient is partly attributed to the relatively poor heat circulation at the angle between the beam and the lower column and partly to

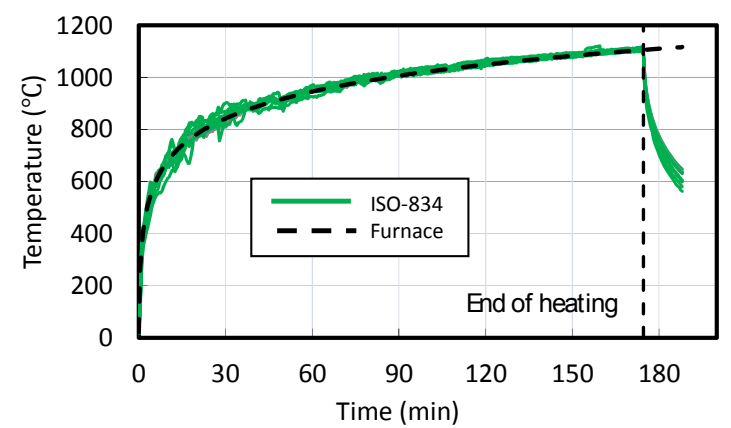

Fig. 7 Furnace internal temperatures vs. ISO 831-1 standard fire curve.
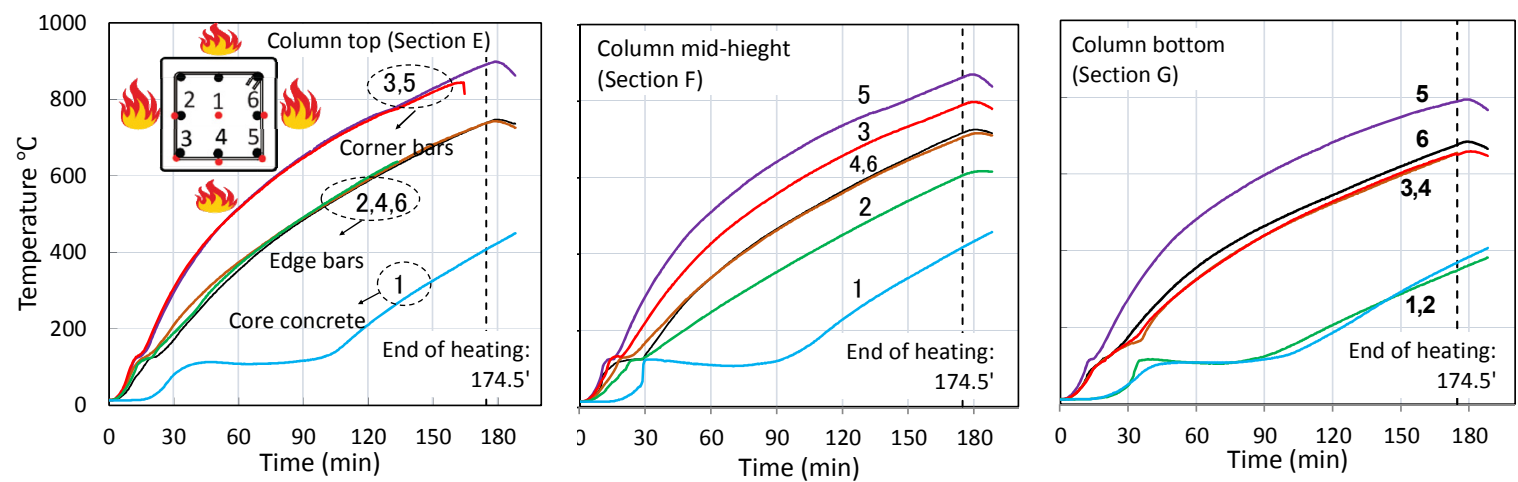

Fig. 8 Internal temperature distributions of beam (RCF1). the adjacent massive unheated upper columns. This low temperature profile was beneficial to the concrete compressive zone of the beam ends as the vulnerability of the outer layers to spalling of concrete decreased. It is interesting to note that despite the sharp temperature rise at the outer layers of concrete in the mid-sections, especially the corners, no spalling of concrete occurred. It is assumed that relatively high permeability of the cast normal concrete as well as the occurrence of cracks released the accumulated pore pressure and prevented the spalling phenomenon.

\subsubsection{Joints and columns}

Figure 9 and Fig. 10 show the internal temperature distributions of the joints and the left lower column. Because of the massive unheated upper column, the joints exhibited cooler temperature profiles compared with the heated lower column (in average $250^{\circ} \mathrm{C}$ cooler longitudinal bars at the end of fire). The joints acted as heat terminals transferring the heat flux from the beam and lower columns to the upper columns. The corner longitudinal steel bars of the heated column attained higher temperatures than the edge bars due to the double face heating. Similar to the beam, the core concrete exhibited temperature stagnations at $100^{\circ} \mathrm{C}$ due to the same phenomenon explained earlier. The relatively low internal temperature distributions of the bottom section of the column is because of the thermally insulated bottom steel beam through which the heat flux was partly dissipated.

\subsection{Structural response \\ 3.3.1 Restrained RC beam}

The continuity between the beams and the columns was expected to generate significant internal forces within the members, especially at the early stages of heating when the fire damage was minor. The RC beams of the test specimens were restrained to axial expansion (axial restraint) and to rotate at it ends (moment restraint). The former generates a considerable amount of axial thrust $P$ as shown in Fig. 11 (Buchannan 2001). The thrust $P$ applies an additional bending moment $P, e$, where $e$ is the eccentricity between the line of action of the thermal thrust and the centroid of the compression block 

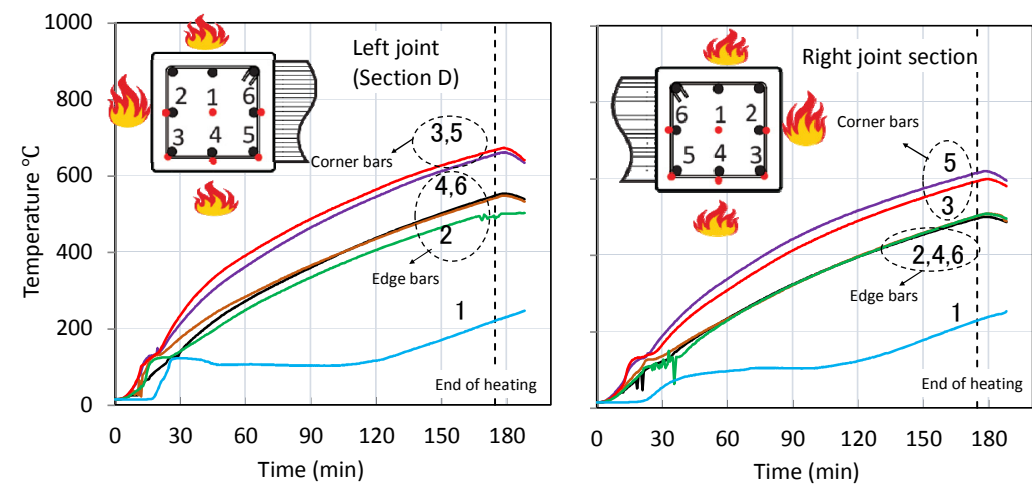

Fig. 9 Internal temperature distributions of joints (RCF1).
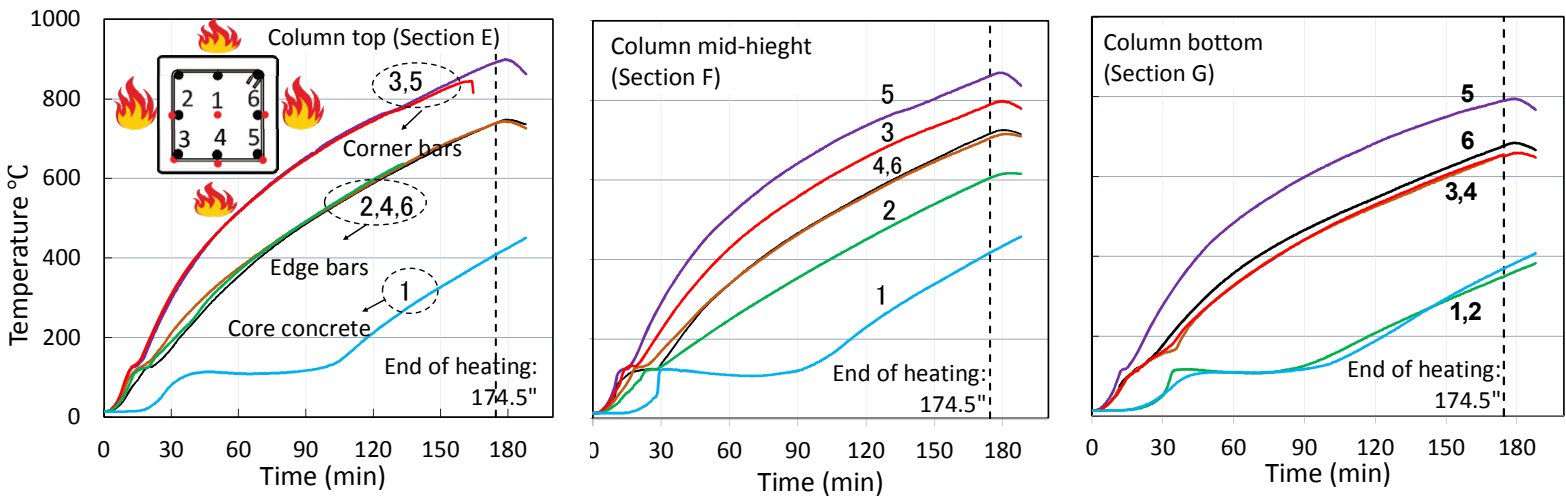

Fig. 10 Internal temperature distributions of left lower column (RCF1).

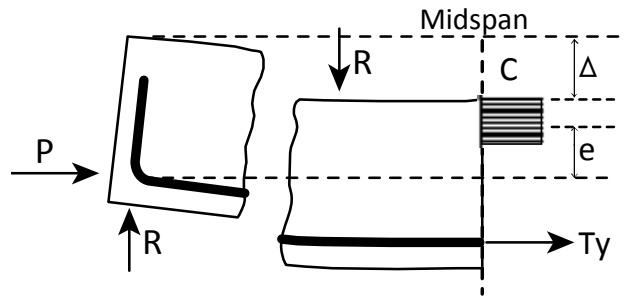

Fig. 11 Free body diagram of a beam with axial restraint force (Buchenon, 2001).

near the top of the beam. The latter induces an additional moment at the supports to encounter the downward deflections at the mid-sections. Figure 12 shows the collapse mechanism of a fixed support beam, which is benefited from the moment restraint effect (Saito 1968). During the early stage of fire, the magnitude of end moment $\left(M_{r}+M_{0}\right)$ at the end of beam increases to the value of bending moment ${ }_{C} M_{y}^{\prime}$, provided that the tensile reinforcement ratio at the beam ends is low enough. As the value of ${ }_{C} M_{y}^{\prime}$ decreases with accordance of the passage of fire time, the $\left(M_{r}+M_{0}\right)$ at the ends lowers and successively reaches ${ }_{C} M_{y}^{\prime},{ }_{C} M_{y}^{\prime \prime}$, and ${ }_{C} M_{y}^{\prime \prime \prime}$. As the total moment of the beam is definite, moment in the centre of span increases until it reaches its bending capacity ${ }_{T} M_{y}^{\prime \prime \prime}$ and the beam collapses.

The installed strain gauges on the top steel beams did not succeed to measure the changes in strain due to the relatively large stiffness of the steel beams. As a result, the magnitude of generated forces during the fire tests

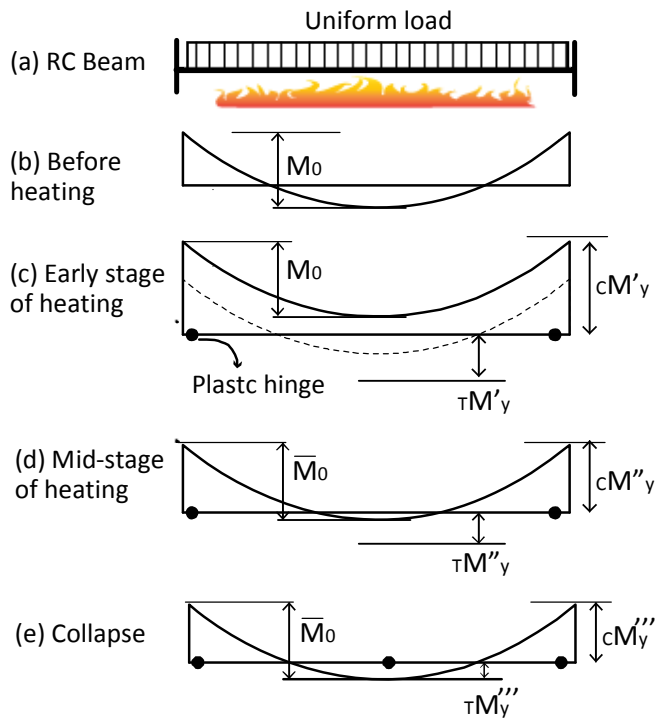

Fig. 12 Redistribution of moments and collapse mechanism of a fixed end beam (Redrawn from Fig. 10 of Saito, 1968).

were not measured. However, the readings from the displacement transducers provided valuable measures by which the fire performance of the test specimens can be discussed. The relative vertical deflection and deflection rate of the mid-span of RCF1 are shown in Fig. 13(a). The term relative deflection here is defined as the subtraction of the vertical displacements of the beam end from those of the beam mid-span. The structural 
response of the beam can be discussed as follows:

Stage 1 (steady deflection): The mid-span's vertical deflection increased almost linearly with time and peaked at $32.75 \mathrm{~mm}$, twelve times larger than the initial one $(2.71 \mathrm{~mm}), 105$ minutes from the start of heating. The total drifts at the bottoms of the upper columns due to expansion of the beam reached $2.8 \mathrm{~mm}$, Fig. 13(b). The measured rotation at the left beam end was roughly two times larger than then right beam end, Fig. 13(c). It seems that the headed anchorage had better performance in fire. Fig. 14 shows the bending moment diagram of the beam together with the moment bearing capacities of the beam end and mid-span sections. For a tensioncontrolled rectangular beam in which all steel reinforcement yields at ultimate capacity, nominal moment capacity as a function of temperature, $M_{u, T}$, can be calculated as (NIST 2009):

$$
\begin{aligned}
& M_{u, T}=A_{s}^{\prime} \cdot f_{y, T}\left(d-d^{\prime}\right)+\left(A_{s}-A_{s}^{\prime}\right) \cdot f_{y, T} \cdot\left(d-\frac{a_{T}}{2}\right)+M_{r, T} \\
& a_{T}=\left[\left(A_{s}-A_{s}^{\prime}\right) \cdot f_{y, T}\right] /\left[0.85 f_{c, T}^{\prime} \cdot b\right]
\end{aligned}
$$

where $A_{s}$ and $A_{s}^{\prime}$ are areas of tension and compression steel, respectively, and $d$ and $d^{\prime}$ are depths of the tension and compression steel centroids, respectively. $a_{T}$ is the depth of the compressive stress block, and $M_{r, T}$ is additional resistance caused by axial and/or rotational thermally induced restraints on the section.

In this study, the reduced section $\left(500^{\circ} \mathrm{C}\right.$ isotherm) method proposed by Anderberg (1978) was adopted, where $f_{c, T}^{\prime}$ is held constant at temperatures below $500^{\circ} \mathrm{C}$, but the size of the effective compression block is reduced. Moreover, the yielding stress of steel at elevated temperatures $f_{y, T}$, was extracted from the experimental results (AIJ 2009). As it is plotted on the BMD, unlike the minor loss of bearing capacity of the beam ends, the mid-sections were expected to lose $70 \%$ of their load bearing capacities. Due the moment restraint effect, the BMD was expected to ascend (moment redistribution: the dotted lines in Fig. 14). The increase in the magnitude of the end moments seemed not large enough to cause plastic hinges.

Stage 2 (exceeding deflection rate limit): 105 minutes after the commencement of fire, the mid-span exhibited sharp downward displacements, which is attributed to the propagation of fire damage to the beam. As can be seen in Fig. 13(c), the right beam end underwent a sudden sharp rotation and following that, the rotation of the left beam speeded up. In this stage the outward-drifting action of the beam gradually decreased and turned to contraction. The ISO-834 deflection limit $\delta=l^{2} / 400 d$ ( $l=$ clear span of the beam and $d=$ distance from the extreme fiber on the cold design compression zone to the extreme fiber on the cold design tension zone of the section) was $68.57 \mathrm{~mm}$ and exceeded 145 minutes from the start of heating in this stage. This stage ended 168 minutes from start of heating when the ISO-834 limiting rate of deflection, $d \delta / d t=l^{2} / 9000$, was exceeded $(3.04 \mathrm{~mm} / \mathrm{min})$. The beam was completely in catenary action. The BMD was expected to descend to its initial pre-fire place due to the progressive damage to the beam ends. The residual moment bearing capacity of the mid-sections was as low as $0.1 M_{u, 20^{\circ} \mathrm{C}}$. It is assumed
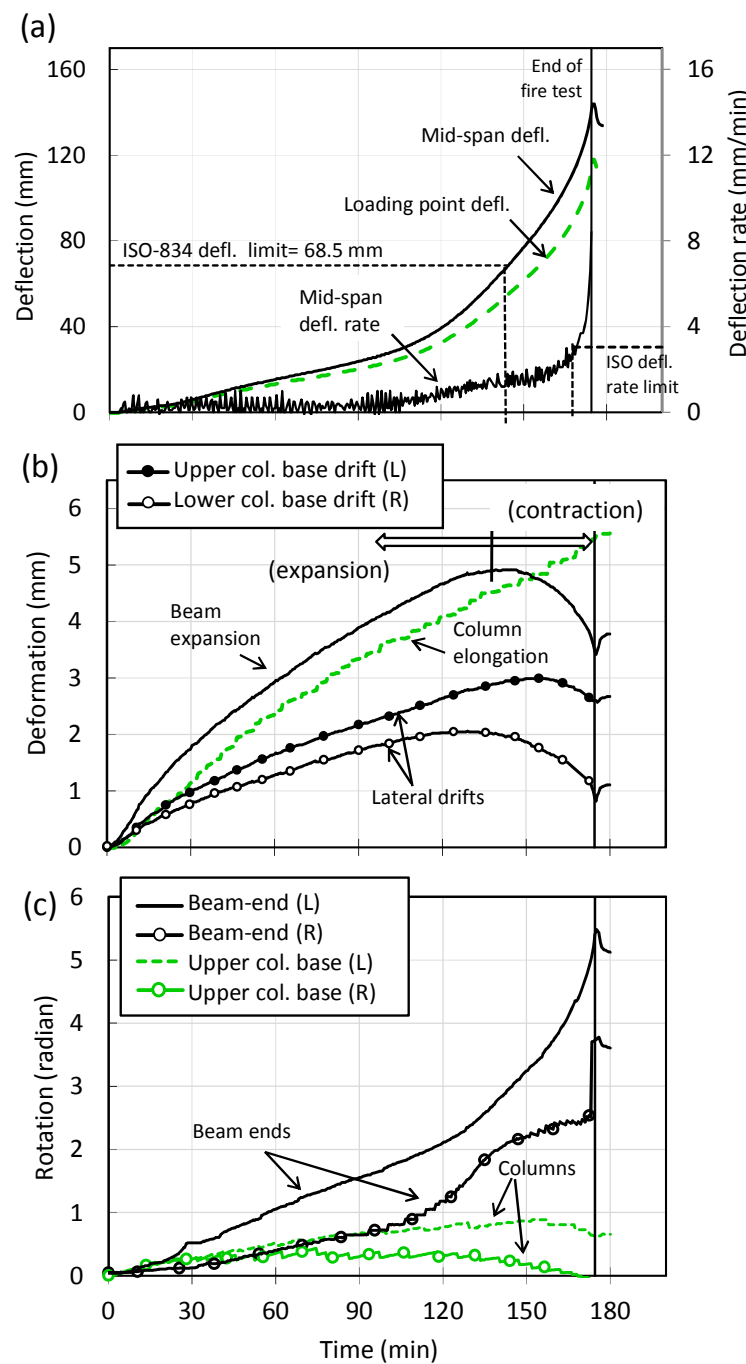

Fig. 13 Structural response of RCF1.

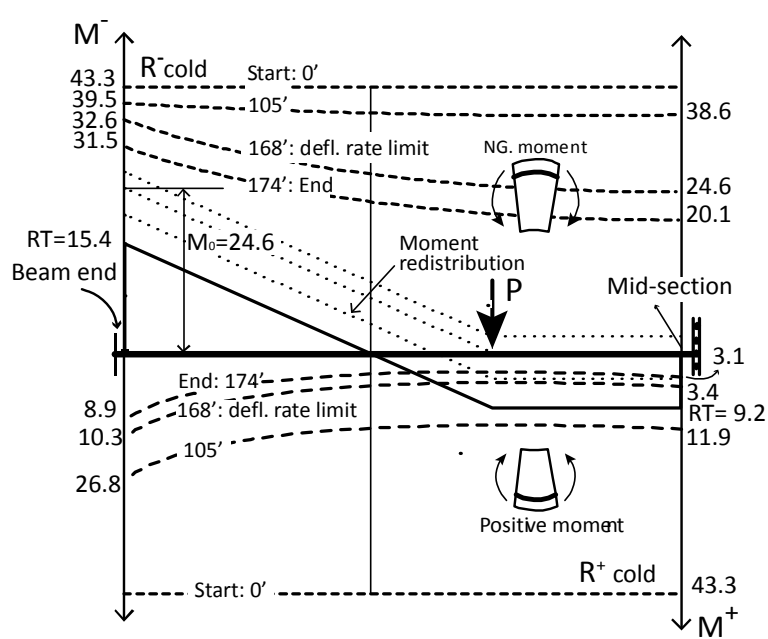

Fig. 14 Bending moment and bending capacities of RCF1 beam. 
that plastic hinge occurred at the mid-span in this stage.

Stage 3 (collapse): The fire test continued a couple of minutes after exceeding the deflection and deflection rate failure criterions by ISO- 834 until the beam could no longer maintain the loads and continuance of the test could damage the test apparatuses. Hence, the fire terminated 174.5 minutes from start of heating. The deflection reached $131.35 \mathrm{~mm}, 48$ times larger than the initial deflection. As it is plotted on Fig. 14, the residual bending moment capacity of the end sections was still in a considerable safety margin.

\subsection{Joints and columns}

As it is demonstrated in Fig. 13(b), the lower columns exhibited almost a linear axial expansion with time as a result of minor axial restraint. On the other hand, the expansion and contraction of the beam caused remarkable deformations on the side columns. It was, however, not confirmed whether the tops of the lower columns yielded. Figure 15 schematically shows the deformed columns and joint together with the redistribution of moment in the lower column and extremal actions on the joint.

The ultimate shear capacity of the joint $V_{j, u}$ at room temperature can be calculated as

$$
V_{j, u}=0.7 F_{j} b_{j} D_{j}
$$

where $F_{j}=0.8 \times \sigma_{B}^{0.7}$ is the shear strength of joint with $\sigma_{B}$ compressive strength, $b_{j}$ is the effective width of joint, and $D_{j}$ can be determined equal to the column width (AIJ 2004).

The temperature profiles of the joints could imply minor loss in $V_{j, u}$ owing to the considerably low temperatures of the core concrete. The shear force demand $V_{j}$ in Fig. 15(b) can be calculated based on the equilibrium of forces on the joint:
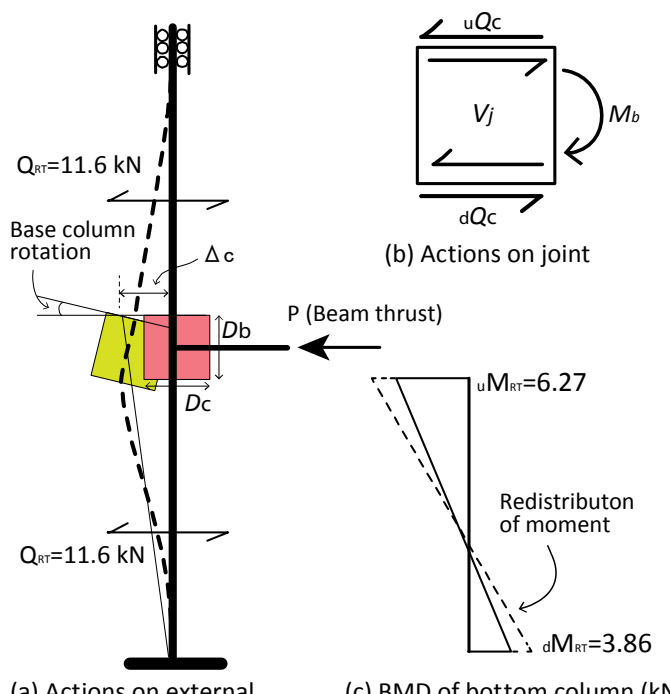

(a) Actions on external beam-column subassemblage

Fig. 15 Shear force and moment distribution on side columns and joint.

$$
V_{j}=\frac{M_{b}}{j_{b}}-\frac{{ }_{u} Q_{c}+{ }_{d} Q_{c}}{2}
$$

where $M_{b}$ is the beam end moment, $j_{b} j_{b}$ is the distance between the tensile and compressive longitudinal reinforcements of the beam, ${ }_{u} Q_{c}$ and ${ }_{d} Q_{c}$ are the shear forces of the upper and lower columns, respectively.

Determining the changes in the magnitude of $V_{j}$ during fire is largely depending on the residual stiffness of the elements attached to the joint (Matsudo et al. 2012). To investigate fire response of the joints and lower columns, the authors carried out a series of fire tests on statically determinate externally beam-column subassemblages. The results will be published elsewhere.

\section{Conclusion}

Fire performance of statically indeterminate $\mathrm{RC}$ frame subjected to service loads was experimentally investigated in this paper. The presented paper is unique as the actual interaction between the beam, joint, and side columns was investigated in details. The following conclusions can be drawn:

The thermal gradient within the frames was nonuniform so that the end-sections of the concrete beam remarkably attained lower temperatures than the midsections, owing to the adjacent unheated massive upper columns and the poor heat circulation at the angle between the beam and the lower column. The internal temperature rise of the joints were significantly smaller than the lower columns.

Despite the sharp temperature rise within the concrete cover of the beams and columns at early heating stages, no concrete spalling occurred. Adequate permeability of the cast concrete and formation of micro cracks were assumed to release the critical internal pore pressure.

Flexural cracks in the mid-sections and shear/flexural shear cracks elsewhere were the dominate damage to the beam. Severe flexural cracks ( $8 \mathrm{~mm}$ Max.) occurred at RCF1 beam ends, which diagonally extended to the joints. The dominant damage to the joints and lower columns of RCF1 was the shear cracks. The integrity of the joints was maintained.

The fire endurance of the beams significantly benefited from the moment and axial restraints by which the magnitude of the positive moment reduced at the early stages of heating. In other words, the bending moment diagram of the beam redistributed to the advantage of the cross-sections between the two loading points. At later fire time steps, as the fire damage progressed the bending moment diagram was expected to return to its initial state and cause plastic hinge in the mid-span.

Roughly 145 minutes after start of heating, the excessive deflection of RCF1 beam overtook the its axial expansion and began a catenary action (contraction phase) through which the beam imposed inward lateral deformations on the side columns.

A few minutes after exceeding the ISO-834 deflection 
rate limit due to the severe fire damage the constant loading was impossible and fire terminated (174.5 minutes). The residual moment capacity of the beam ends was expected to govern the collapse, if the lower columns did not collapse earlier.

The lower columns under axial and lateral forces did not exhibit any second order effects such as buckling or shear failures. It is experimentally confirmed that the seismic design detailing can effectively accommodate the thermally induced shear forces.

\section{Acknowledgements}

Part of the investigation work was supported by Grantin-Aid for Scientific Research (A) of Japan (23246101). The authors would like to thank Dr. Sungjun Lim, Mr. Zhong Hui, and Mr. Ota Shohei for their great contribution to this research. We thank the GBRC for assisting the research with the proper fire test facilities.

\section{References}

AIJ, (1998). "Standard for structural design and construction of prestressed concrete structures." Appendix 9, Fire performance of prestressed concrete, revised edition. (in Japanese).

AIJ, (2004). "Design guidelines for earthquake resistant $R C$ buildings based on inelastic displacement concept." 399. (in Japanese)

AIJ, (2009). "Guidebook for fire resistive performance of structural materials." 158. (in Japanese)

AIJ, (2010). "Standard for structural calculation of reinforced concrete structures." revised edition. (in Japanese)

Anderberg, Y., (1978). "Analytical fire engineering design of reinforced concrete structures based on real fire characteristics." Proc. FIP Eight Congress, International Federation for Prestressing, Lausanne, Switzerland.

Bailey, C. G., (2002). "Holistic behaviour of concrete buildings in fire." Structures and Buildings 152(3), 199-212.

Bisby, L., Mostafaei, H. and Pimienta, P., (2014). "State-of-the-art on fire resistance of concrete sructure Structure-Fire Model Validation."

Buchanan, A., (2001). "Structural design for fire safety." John Willey \& Sons Inc., 161.

Chana, P. and Price, B., (2003). "The Cardington fire test." Concrete, 37 (1), 28-33.

Fang, L.-K., Sullivan, P. J. E., Lee, C.-C., Fang, I.-C., Yeh, T.-Y. and Wu, M.-Y., (2012). "Fire resistance of beam-column subassemblage." ACI Structural Journal, 109, 31-40.

Fletcher I. A., Borg, A., Hitchen, N., and Welch, S., (2006). "Performance of concrete in fire: a review of the state of the art, with a case study of the Windsor tower fire." BRE Research Publications.

Gustaferro, A. H. and Martin, L. D., (1977). "PCI design for fire resistance of precast prestressed concrete." Prestressed Concrete Institute, USA.

ISO 834-1, (1999), Fire resistance tests - Elements of building constructions - Part1: General requirements." 1st edition.

Luo, M. C., Yin, Y. Z., Lamont, S. and Lane, B., (2005). "Eastern solutions, Focus: building design." Fire Protection; Fire Engineers Journal, 393 29-31.

Matsudo, M., Satoh, Y., Sasaki, H., Hirashima, T. and Iguchi, S., (2012). "Fire resistance of hybrid structures com,posed of reinforced concrete columns and steel beams." Journal of Structural and Construction Engineering, Transactions of AIJ, 1463-1471. (in Japanese)

National Institute of Standards and Technology, (2009). "Best practice guidelines for structural fire resistance design of concrete and steel buildings." NISTIR 7563, Gaithersburg, MD.

Saito, H., (1968). "Fire resistance of fixed end beams." Journal of Structural and Construction Engineering, Transactions of AIJ, 761 762. (in Japanese)

Takeichi, N. and Minegishi, Y., (2015). "Fire safety design on the performance-based for skyscraper - a case in Japan." Proceedings of the 10th Asia-Oceania Symposium on Fire Science and Technology, Tsukuba.

Wang, Y., Burgess, I., Wald, F. and Gillie, M., (2012). "Performance-based fire engineering of structures." CRC press, New York, USA, Chapter 1, 6 - 7.

Xiao, J.-Z., Li, J. and Huang, Z.-F., (2008). Fire response of high-performance concrete frames and their post-fire seismic performance." ACI Structural Journal, 105, 531-540. 